Journal of Thermal Engineering, Vol. 7, No. 3, pp. 623-634, March, 2021

Yildiz Technical University Press, Istanbul, Turkey

\title{
NUMERICAL INVESTIGATION OF HEAT TRANSFER WATER-COOLED ROOF IN AN ELECTRIC ARC FURNACE
}

\author{
Mamdouh El Haj Assad ${ }^{1 *}$, Khalil Khanafer ${ }^{2}$, Ehab Hussein Bani Hani², Bashria Yousef ${ }^{1}$
}

\begin{abstract}
One of the major problems in electric arc furnace is the high temperature which results in thermal stresses and cracks within the material of the furnace surrounding walls. An effective cooling technique is needed to avoid such problems. For this purpose, a novel roof configuration of an electric arc furnace is used to provide efficient cooling to reduce the temperature in the roof material. The roof consists of two solid materials, namely, copper and alumina brick. The roof cooling is achieved by a water circulation within the roof. A numerical model using finite element method was implemented to solve the heat conduction equation with the complicated boundary conditions to find out the effects of using brick material with geometrical size variations for different values of thermal conductivity on the temperature distribution within the roof. The results showed that the decrease in brick material thermal conductivity resulted in a significant decrease in the top surface temperature of the furnace roof. The results showed that rectangular brick material is the best option in the roof to keep it at low temperature.
\end{abstract}

\section{Keywords: Electric Arc, Furnace, Heat Transfer, Temperature}

\section{INTRODUCTION}

Electric arc furnaces (EAFs) are an advanced technology in the production of iron and steel, which began to be used in the late seventies and early eighties of the last century [1, 2]. EAFs are used to heat the materials installed in the furnace by an electric arc. The temperature of the EAF can be up to $1800 \mathrm{oC}$. Only $32 \%$ of the steel factory in the world used the EAF due to its expensive cost compared to the traditional furnaces. The EAF is composed of three parts, the shell which includes walls and lower bowl, the main part and the roof part which is well insulated or water cooled [3].

Various models have been presented to describe the design of EAF [4-6]. In EAF more than $90 \%$ of the power converts to heat radiation flux [7]. Distribution of the generated heat radiation flux along surface metal, walls, and roof is main factor to find the efficiency of EAF. Heat radiation flux to the metal surface is the useful energy that consumed for melting the metal, while the radiation flux to the wall and roof are considered as a power loss [8]. Reliable cooling for EAF will increase productivity; on the other hand, it will contribute to the heat losses. Many of furnace cooling designs to increase the productivity, furnace sustainability and reduce the wear rate of linings have been studied and applied. The integration of cooling designs includes analysis of the process specifications, selection or development of appropriate cooling design, installation, operating, monitoring, and evaluation of cooling design.

The main classes of the different developed design of cooling system have been presented by Karel et al. [9] as spray coolers, plate coolers, stave coolers, internal block, panels and external jackets. Khodabandeh et al. [10] proposed experimental and numerical analyses for the convection and radiation heat transfer in the electric arc furnace using oxygen blowers. The numerical results revealed that the useful life of the cooling box front panel is reduced due to poor cooling. Chirattananon and Gao [11] used a mathematical model to evaluate the electric arc furnace performance using the integration of electric and thermal models. It was found that minimum or maximum energy output can be obtained by controlling voltage and electric current. Gharib et al. [12] used transient conjugate heat transfer analysis of the cooling panel pipe to find out the crack generation reasons. The results of this study showed

This paper was recommended for publication in revised form by Regional Editor Rashmi Walvekar ${ }^{1}$ Department of Sustainable and Renewable Energy Engineering, University of Sharjah, United Arab Emirates

${ }^{2}$ Mechanical Engineering Department, Australian College of Kuwait, Mishref, Kuwait

*E-mail address: massad@sharjah.ac.ae

Orcid id: 0000-0001-6311-7925, 0000-0002-7765-6097, 0000-0002-7102-7679, 0000-0002-9569-5903

Manuscript Received 29 January 2019, Accepted 8 June 2019 
that severe thermal stresses and crack caused in the pipe peripheral direction due to the high temperature gradients in the pipe bends.

Bisio et al. [13] studied the thermal behavior, power saving as well as the control of pollution in an Ultra High Power electric arc furnace. The study used two different materials for panels (copper and steel) of thickness $0.01 \mathrm{~m}$ with internal temperature of $100^{\circ} \mathrm{C}$. Their results showed that the thermal losses decreased sharply with the increase in the slag melting temperature adhering to the shell of the electric arc furnace shell.

Nikolov [14] investigated the effects of voltage and current at the arc combustion start and end, respectively, to find out the formation of weld overlay clad surfaces. It is found from his research that the amplitude of vibrations has the most important effect on the vibro arc process. Other researchers focused on plasma processing and handling in plasma arc welding $[15,16]$. In general, furnace modeling is a complicated process due to the complexity of the furnace cooling system embedded within the roof or the wall of the furnace. A three-dimensional analysis has been conducted to analyze the heat transfer and flow characteristics within electric furnace used for glass melting process [17]. A more simplified model for engineers using two-dimensional mathematical modeling followed by experimental work has been presented to determine the radiation heat transfer in a furnace using pulverized coal [18].

The electric arc furnace life refers to the life of furnace roof. With the expansion of steel-making electric arc furnace capacity and the increase of unit power, the working conditions of the furnace roof become more demanding. This paper will introduce a model of cooling by applying a layer of high alumina brick (Al2O3) in the roof of the arc furnace. Different dimensions and thermal properties of the alumina refractory brick will be tested in this investigation to show its effect on the temperature of the roof's top surface. Where many experimental techniques are used to test the welding process such as spectroscopic methods and multidirectional monochromatic imaging methods [19-22]. Thus experimental and numerical methods are widely used in arc welding [23-25] where the results can be compared for further investigations, mainly for newly developed arc welding techniques such as the laser hybrid welding process [26] where it increased welding velocity and improved bridgeability to gap and misalignment tolerances.

A heat transfer analysis of an electric arc furnace with a cooling system made of tubular panel has been presented [27] where the temperature distribution was obtained. In this study, 14 tubular panels were used to cover the furnace walls. Thermal analysis of an electric arc furnace has been proposed based on radiative heat transfer within the furnace [28], in other words the system took into consideration only the radiation heat transfer between the hot gas and the furnace walls. A CFD model combined with thermal model has been presented to investigate the effects of the geometrical parameters of an electric arc furnace on the temperature and cooling fluid velocity distributions in the roof panel piping system [29]. CFD modelling has been used as an effective tool to provide an approximate overview of biomass grate furnaces [30]. Another effective tool in determining the furnace performance is exergy analysis which has been used to analyze the performance of furnace-air preheater combined system in a petrochemical plant [31].

In this work, a new design of the furnace roof is presented, which consists of insulation, high conductive material and water tube. The design uses solid media as a heat sink and to force the heat flow toward the water pipes inserted within the rod. From mathematical point of view, it is impossible to get an analytical solution for this complicated physical problem due to the non-homogeneous geometry and due to the presence of the three modes of heat transfer, namely radiation, conduction and convection. The work is aiming to find the best fit solution for the furnace cooling applications.

\section{THEORY}

The schematic diagram of the roof of an electric arc furnace is shown in Figure 1. The roof slanted part (bottom left side) is made of alumina brick with thickness B on its left surface and width $\mathrm{L}$ on its upper surface, and the rest of the roof is made of copper where a water pipe is installed for cooling purposes. A two-dimensional model of the electric arc furnace roof is simulated in this investigation. As such, symmetry boundary conditions were utilized in this investigation. The left wall and right walls were assumed symmetric and water is flowing through the water- 
cooled pipes. The top wall of the roof is exposed to ambient temperature while the bottom surface of the roof is exposed to a very high temperature gas from the electric furnace.

To increase the heat transfer by the circulating water, refractory brick materials with low thermal conductivity (alumina brick materials) are used in this model. Based on the above considerations, the following heat conduction is implemented:

$$
\frac{\partial T}{\partial t}=\frac{k}{\rho c_{p}} \nabla^{2} T
$$

where $T$ is the temperature, $k$ the thermal conductivity, $c_{p}$ the specific heat and $\rho$ is the density. The heat transfer occurs between the gas and the bottom surface of the furnace mainly by radiation, and between the roof upper surface and air by convection, hence the boundary conditions for this can be summarized as follows, respectively

$$
\begin{gathered}
y=0 \rightarrow h_{r} A\left(T_{\text {furnace }}-T\right)=-k \frac{\partial T}{\partial y} \\
y=H \rightarrow h_{\infty} A\left(T-T_{\infty}\right)=-k \frac{\partial T}{\partial y}
\end{gathered}
$$

where $h_{r}$ is the radiation heat transfer coefficient and it is function of the roof bottom surface temperature, $h_{\infty}$ is the convective heat transfer coefficient.

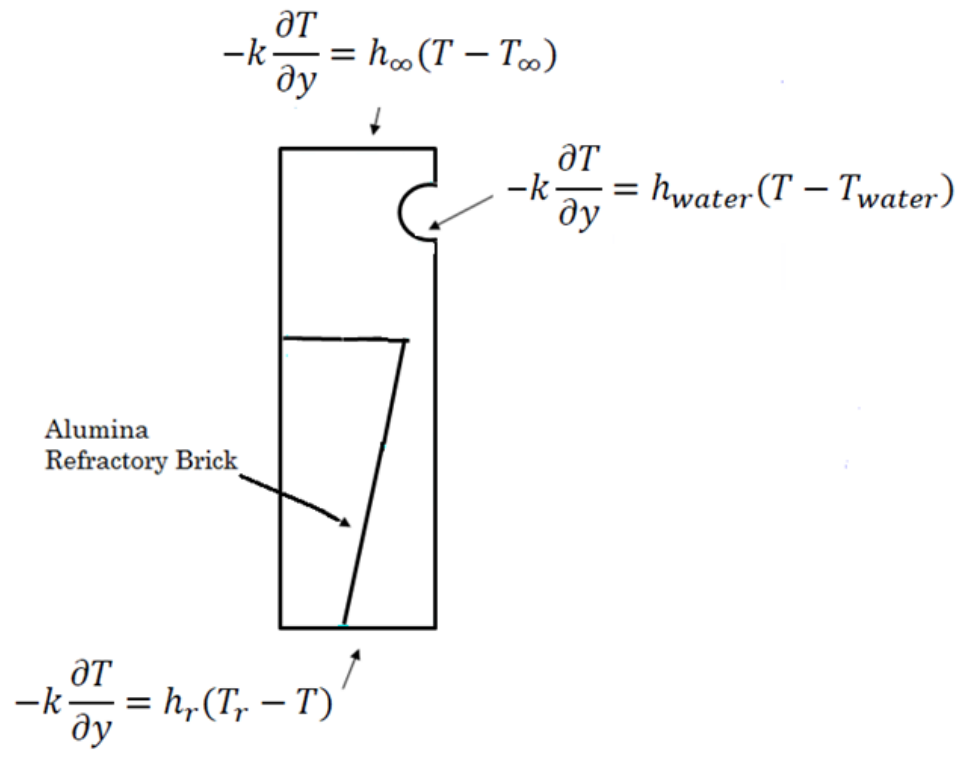

Figure 1. Schematic diagram of the physical problem

The conduction heat transfer is equal to the convection heat transfer at the pipe interface as:

$$
-k \frac{\partial T}{\partial n}=h_{\text {water }} A\left(T-T_{\text {water }}\right)
$$


The boundary conditions used for the symmetry walls, which means the left side of the furnace is insulated and the right side of the furnace is insulated except at the pipe interface, these types of boundary conditions are expressed mathematically by:

$$
\frac{\partial T}{\partial n}=0
$$

In the proposed model it is assumed that the temperature distribution is 2-dimensional steady state, and the thermal properties of the materials are constant. The heat conduction equation presented by Equation (1) subjected to the boundary conditions given by Equations (2-5) is solved using Galerkin method as a finite element technique. A non-uniform grid was generated and used to take care of the fast variations in the dependent variables. These fast variations are due to the steep gradients within the boundary layer in the nearness of the boundaries. 1630 nodes of the non-uniform mesh were used to solve the heat conduction equation and generated grid-independence results as depicted in Figure 2. The discretized equations were solved using the Newton-Raphson method. The steady state solution of the temperature distribution of the proposed geometry Figure 1 is obtained when the dependent variable difference between two iterations satisfied the following equation

$$
\sum\left|\lambda_{i, j}^{\gamma+1}-\lambda_{i, j}^{\gamma}\right| / \sum\left|\lambda_{i, j}^{\gamma+1}\right| \leq 10^{-4}
$$

where $\lambda_{i, j}^{\gamma}$ stands for the dependent variables at iteration $\gamma$.

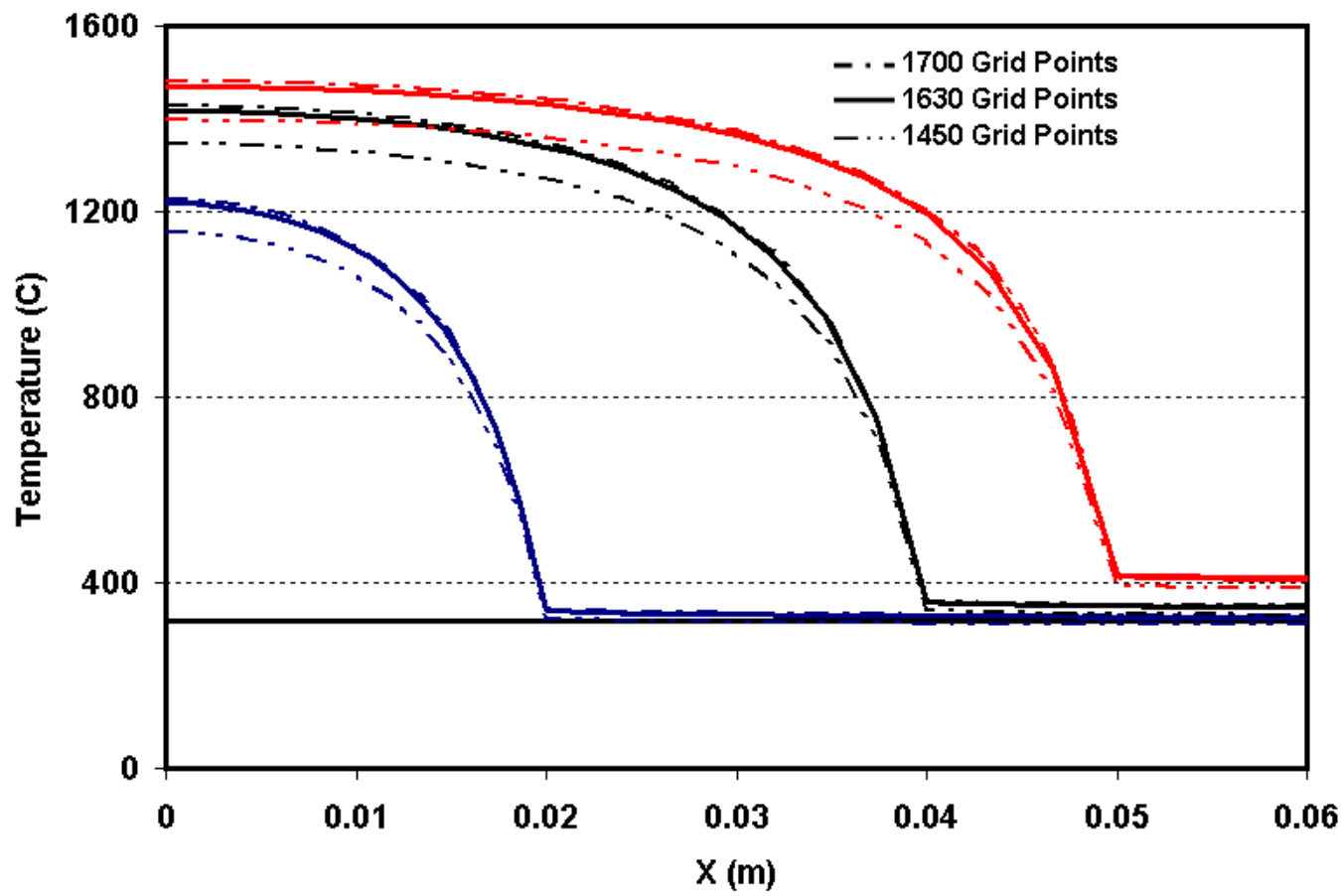

Figure 2. Grid-independence test on the effect of brick material thickness on the bottom wall temperature ( $\mathrm{k}=2.9$

\section{RESULTS AND DISCUSSION}

$\mathrm{W} / \mathrm{mK})$

The circulating water temperature is at $45^{\circ} \mathrm{C}$ flowing at a velocity of $4 \mathrm{~m} / \mathrm{s}$ within a $24 \mathrm{~mm}$ pipe diameter. For these values, the convective heat transfer coefficient on the water side is $13900 \mathrm{~W} / \mathrm{m}^{2 \circ} \mathrm{C}$. The presence of the insulation material will prevent the heat flux to pass through it and hence it will force the heat flux to pass through the copper material toward the water tube so the water will carry the heat within it. 
The maximum temperature occurs at the bottom surface of the insulation material and it is exactly located at the left corner of the bottom surface because the left side of the furnace roof is completely insulated. As we go far away for the left side of the furnace toward the copper material, the temperature starts to decrease due to the presence of water tube on the right side of the furnace roof. On the upper surface of the roof, the temperature will be maximum at the left corner of that surface and the minimum temperature will be minimum at the right corner due to the presence of the water tube on the right side of the roof.

Due to the existence of the hot gas at very high temperature below the roof, the heat flow from the gas to the roof will be mainly due to radiation. The radiative heat flux from the hot gas flowing into the bottom surface of the furnace roof is expressed as [32]

$$
\phi=A \frac{\varepsilon_{w} \varepsilon_{d} \sigma}{\left\{1-\left(1-\varepsilon_{w}\right)\left(1-\varepsilon_{d}\right)\right\}\left(T_{g}^{4}-T_{w}^{4}\right)}
$$

where A is the bottom surface area, $\varepsilon_{w}$ is the bottom surface emissivity, $\varepsilon_{d}$ is the hot gas (dust cloud) emissivity, $\sigma$ is Stefan-Boltzmann constant, $T_{w}$ is the bottom surface temperature and $T_{g}$ is the hot gas temperature in the furnace. The emissivity of hot gas is 0.149 and the emissivity of the alumina brick is 0.6 . The heat flux from the bottom surface is flowing up straight through the copper material, as it reaches the upper surface of the insulation material height, it flows toward the water tube and toward the upper surface through the copper material.

In this investigation, the roof of the electric arc furnace is made of copper material to enhance heat transfer. Figures 3 and 4 show the effect of varying the thermal conductivity of the refractory brick material on the bottom and top surfaces of the furnace roof. It can be seen from Fig. 3 that in the absence of any thermal shield material, the refractory brick has similar thermal conductivity to the pipes $\left(\mathrm{k}=380 \mathrm{~W} / \mathrm{m}^{\circ} \mathrm{C}\right)$, the bottom surface of the roof has a constant temperature $\left(317^{\circ} \mathrm{C}\right)$. As the thermal conductivity of refractory brick decreases, the effect of the thermal shield is more profound and this is manifested by its significant increase in temperature. Figure 3 shows the effect of reducing the thermal conductivity of the refractory brick material on the top surface of the roof. It is noticed from this figure that the maximum temperature of the top surface decreases significantly (from $120^{\circ} \mathrm{C}$ to $84.4^{\circ} \mathrm{C}$ ) with a decrease in the thermal conductivity from $380 \mathrm{~W} / \mathrm{m}^{\circ} \mathrm{C}$ to $2.9 \mathrm{~W} / \mathrm{m}^{\circ} \mathrm{C}$.

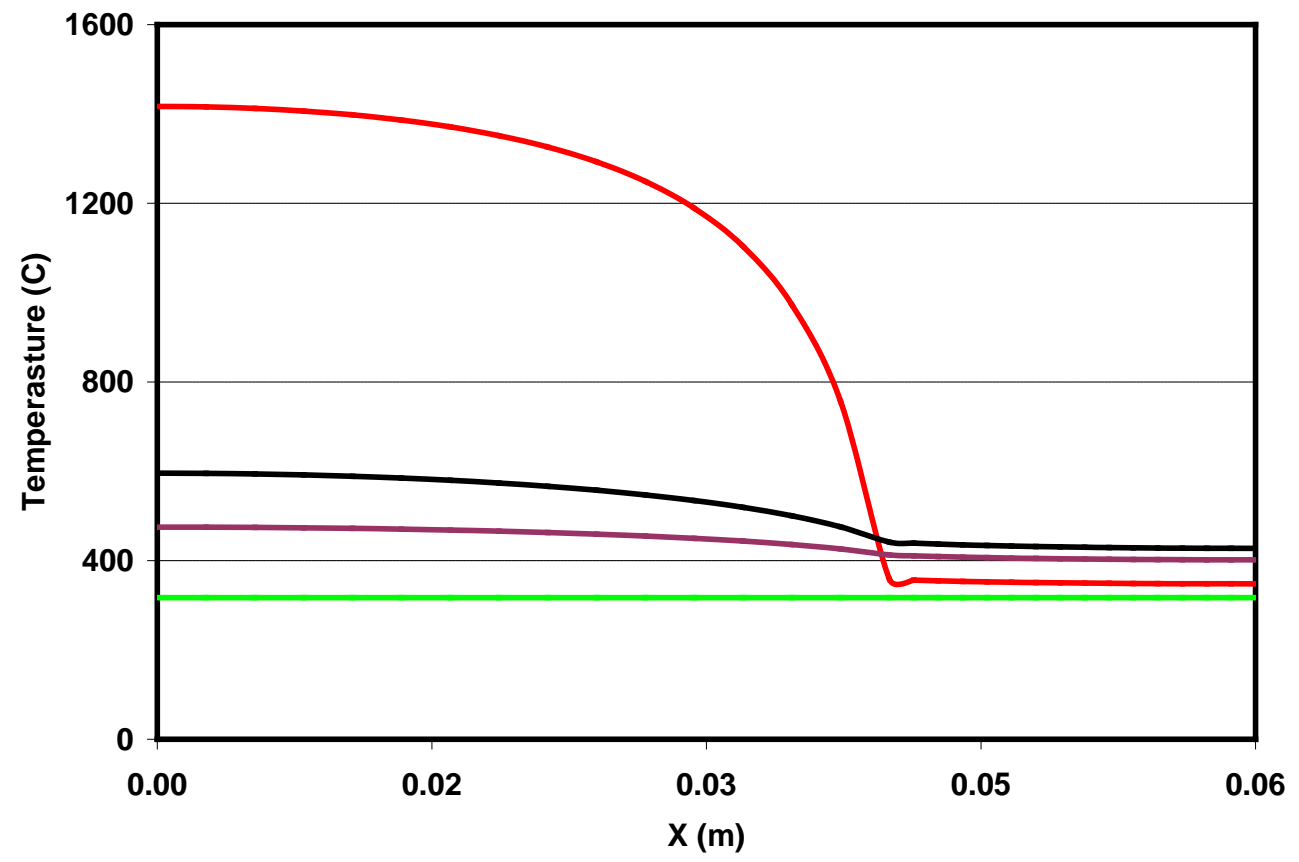

Figure 3. Effect of thermal conductivity of brick material on the bottom wall temperature 


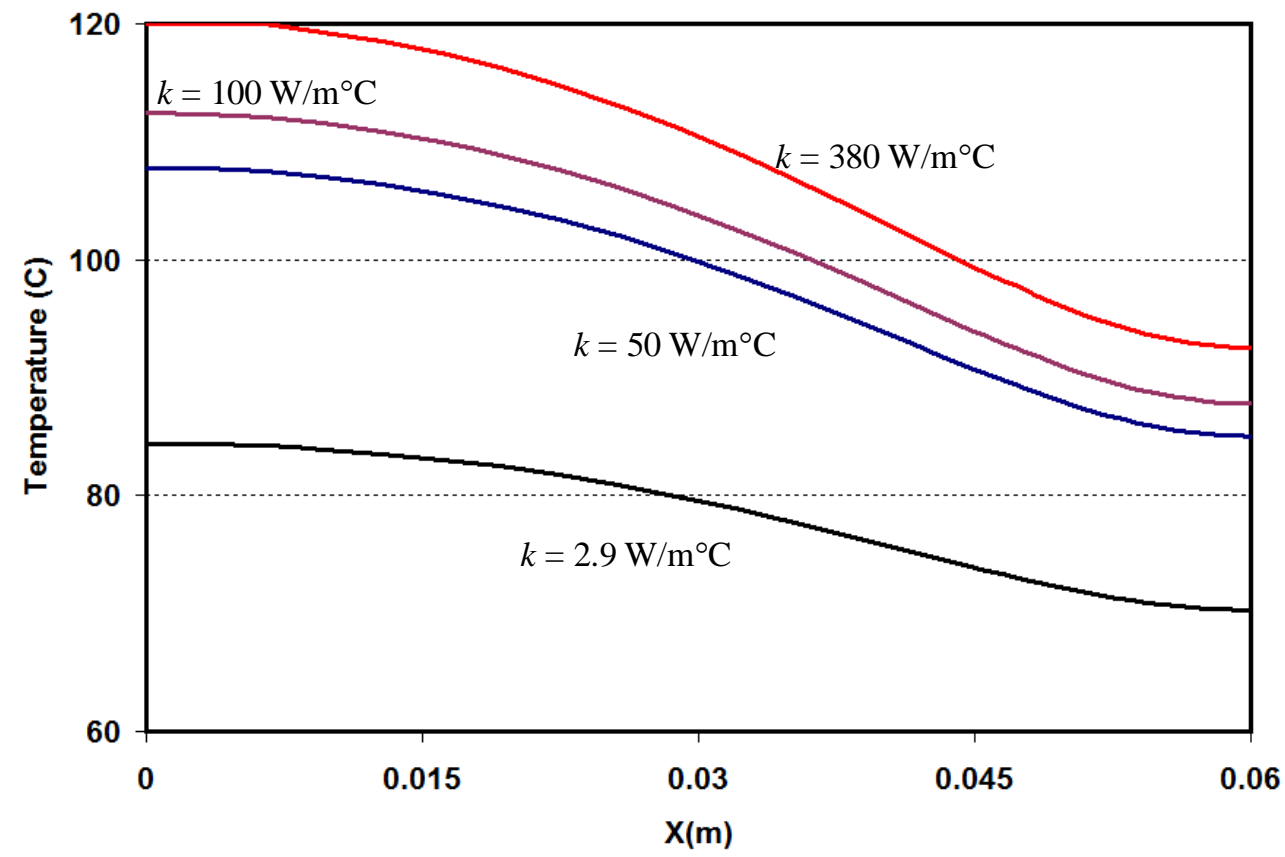

Figure 4. Effect of thermal conductivity of brick material on the top wall temperature

Figure 5 illustrates the impact of thermal conductivity of refractory brick material on the isotherms. Low thermal conductivity material is found to resist heat transfer by conduction through the roof and limit it to the refractory brick material and consequently lower the temperature of the top surface.
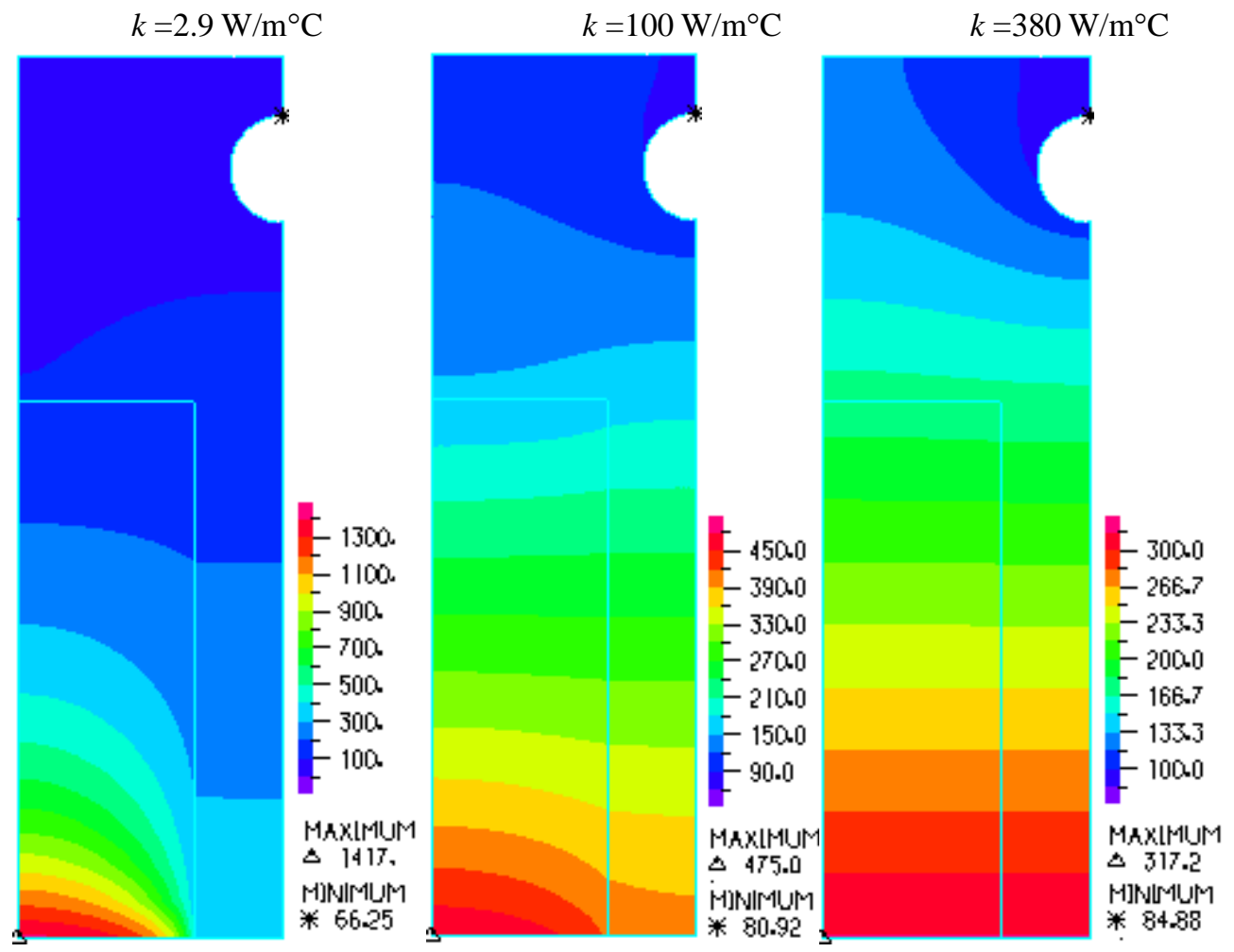

Figure 5. Effect of thermal conductivity of brick material on isotherms 
Figures 6 and 7 demonstrate the effect of varying the thickness of the refractory brick material on the temperature variations along the bottom and top surface of the roof. Figure 5 shows that the bottom surface temperature of the refractory material increases with an increase in the thickness. Moreover, lower maximum top surface temperature is exhibited $\left(73^{\circ} \mathrm{C}\right)$ for large thickness of the refractory material $(B=50 \mathrm{~mm})$. Figure 8 shows the effect of the refractory material thickness on the isotherms. This figure illustrates that the thickness of the brick material has a profound effect on the isotherms.

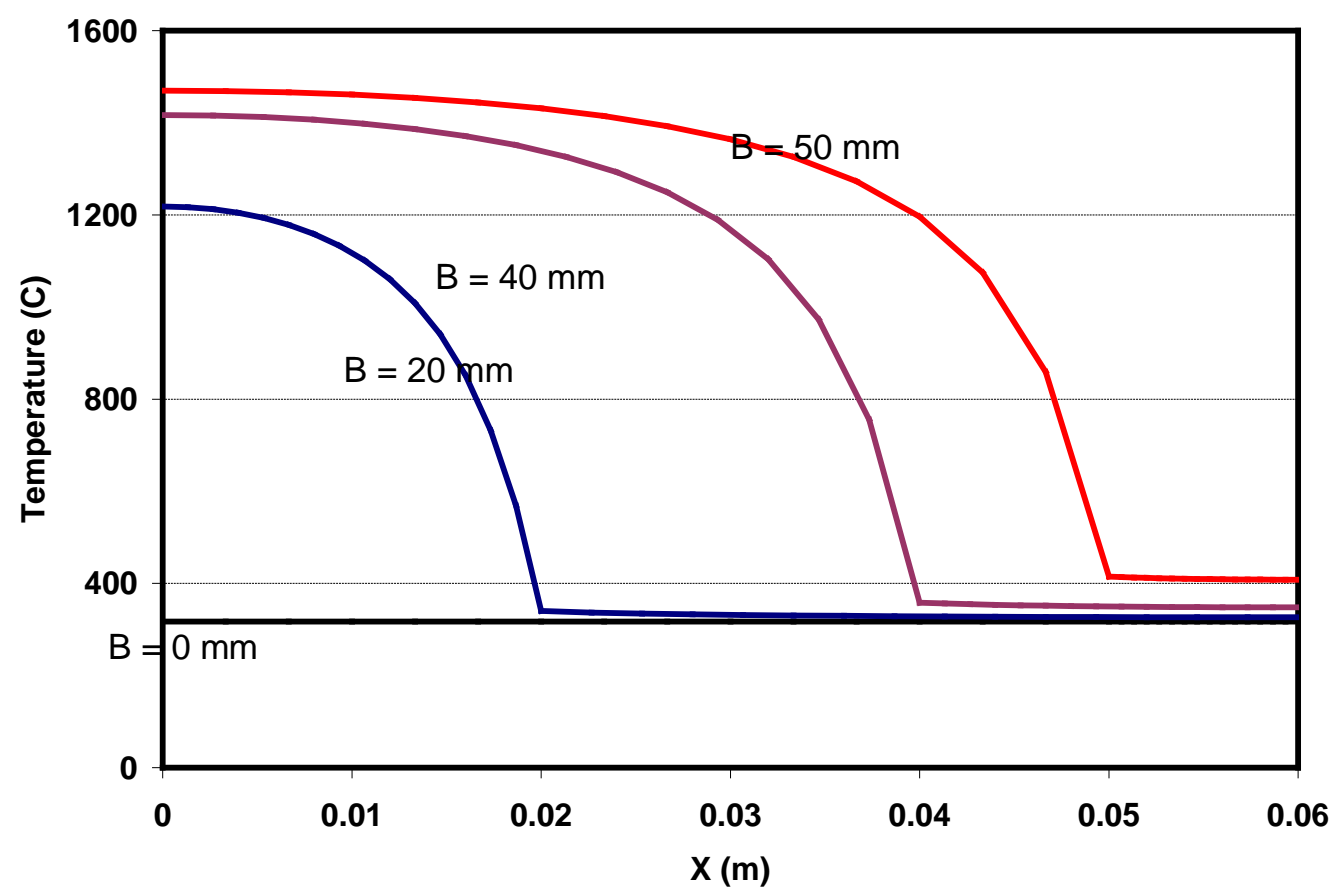

Figure 6. Effect of brick material thickness on the bottom wall temperature $\left(k=2.9 \mathrm{~W} / \mathrm{m}^{\circ} \mathrm{C}\right)$

Figures 9 and 10 illustrate the effect of using wedge brick material on the bottom and top temperatures as well as the isotherms for various sizes. It is noticed from these figures that the application of refractory materials reduces significantly the maximum temperature of the top surface. Figure 8 shows that the maximum temperature of the bottom surface increases from $687^{\circ} \mathrm{C}$ to $1340^{\circ} \mathrm{C}$ with an increase in the dimensions of the refractory material. However, the maximum top surface temperature decreases from $118{ }^{\circ} \mathrm{C}$ to $93.6{ }^{\circ} \mathrm{C}$. This confirms that rectangular refractory material exhibits lower maximum top surface temperature compared with wedge materials. Finally, Fig. 11 shows again the isotherms for various dimensions of the wedge refractory material.

It is worth mention that due to the novelty of this proposed design, there is no such existing design yet, hence no experimental work conducted regarding this system which is only analyzed from mathematical point of view. 


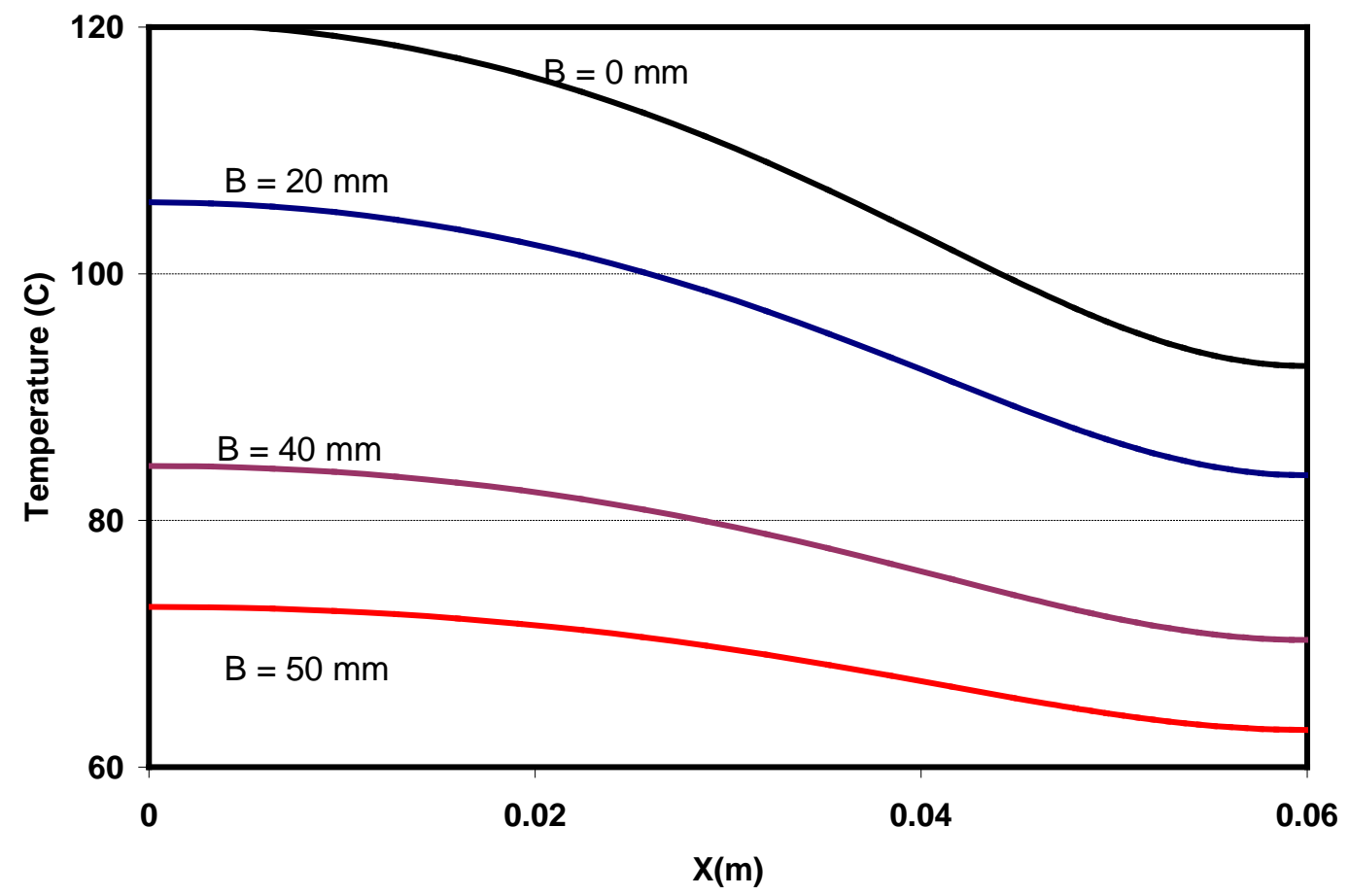

Figure 7. Effect of brick material thickness on the top wall temperature $\left(k=2.9 \mathrm{~W} / \mathrm{m}^{\circ} \mathrm{C}\right)$

$\mathrm{B}=0 \mathrm{~mm}$

$\mathrm{B}=20 \mathrm{~mm}$

$\mathrm{B}=40 \mathrm{~mm}$

$\mathrm{B}=50 \mathrm{~mm}$
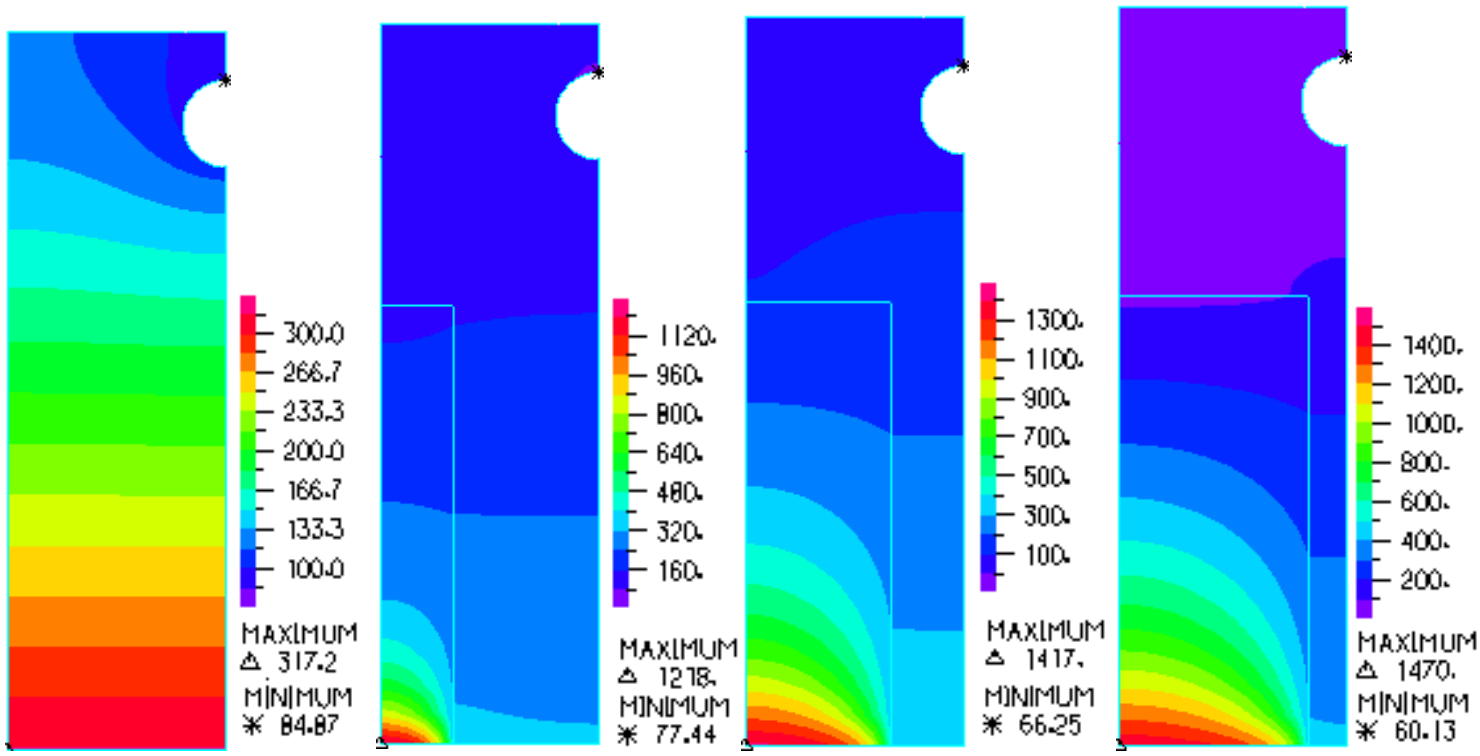

Figure 8. Effect of brick material thickness on the isotherms $\left(k=2.9 \mathrm{~W} / \mathrm{m}^{\circ} \mathrm{C}\right)$ 


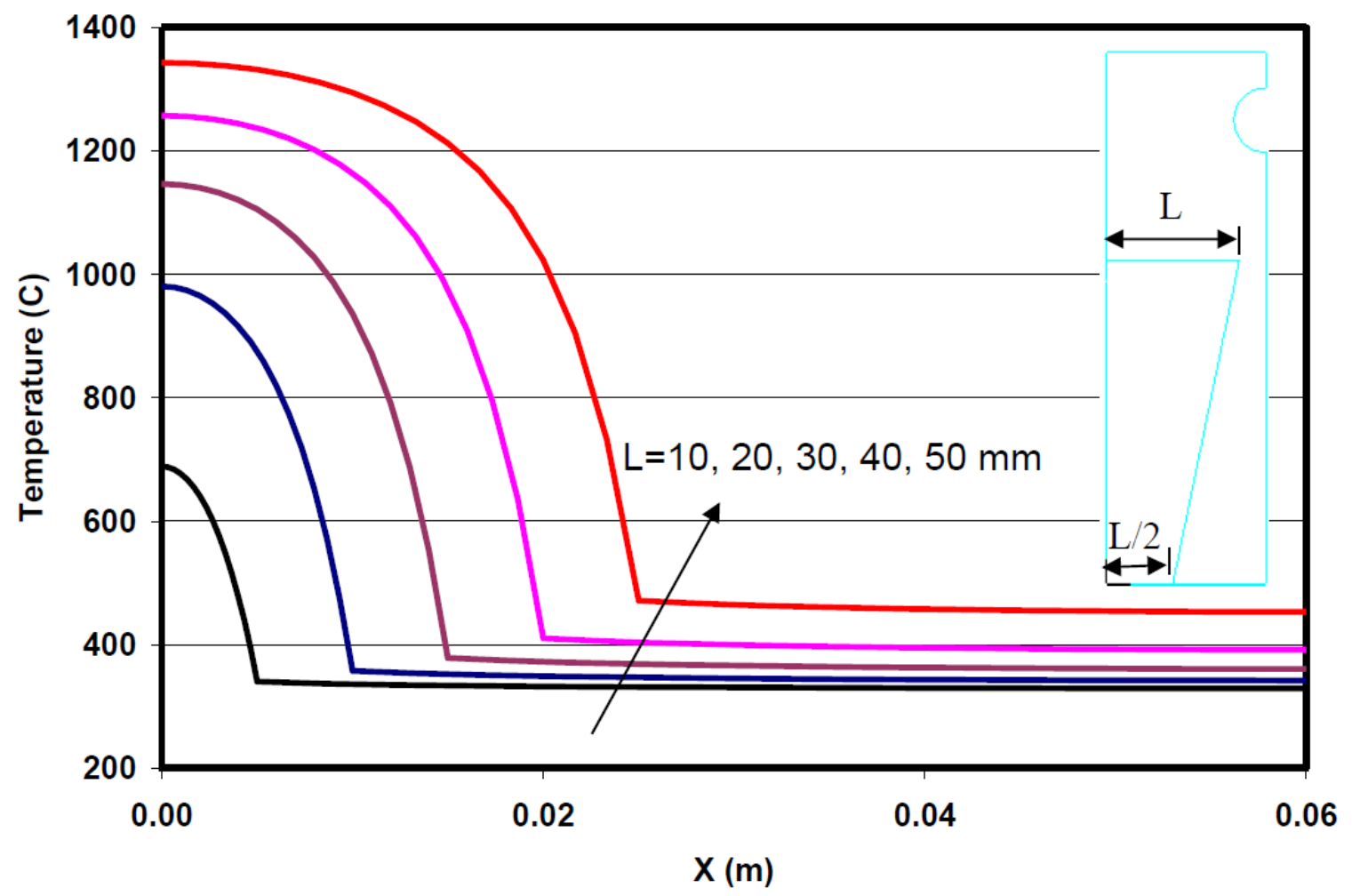

Figure 9. Effect of slanted brick material thickness on the bottom wall temperature $\left(k=2.9 \mathrm{~W} / \mathrm{m}^{\circ} \mathrm{C}\right)$

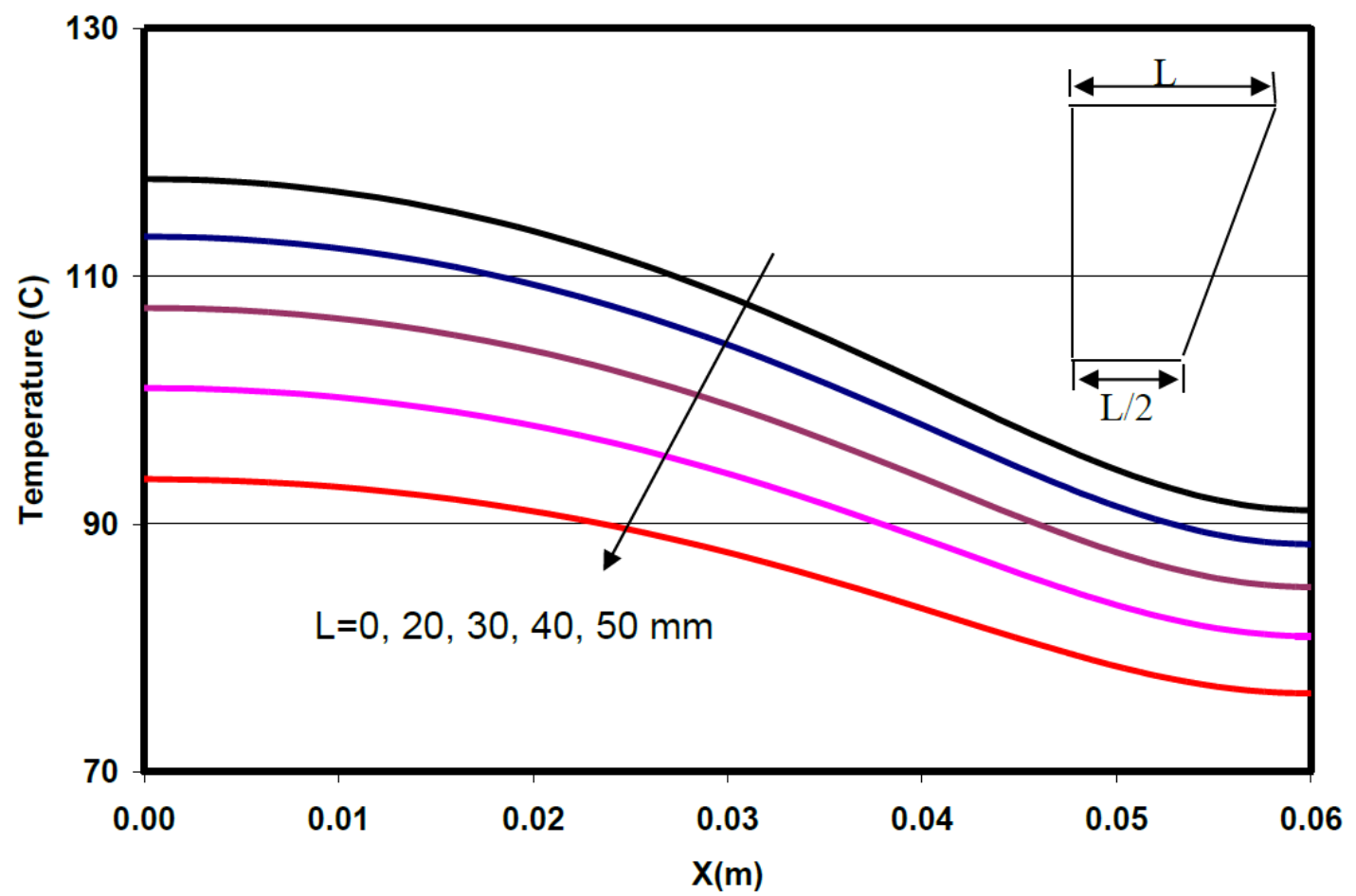

Figure 10. Effect of slanted brick material thickness on the top wall temperature $\left(k=2.9 \mathrm{~W} / \mathrm{m}^{\circ} \mathrm{C}\right)$ 

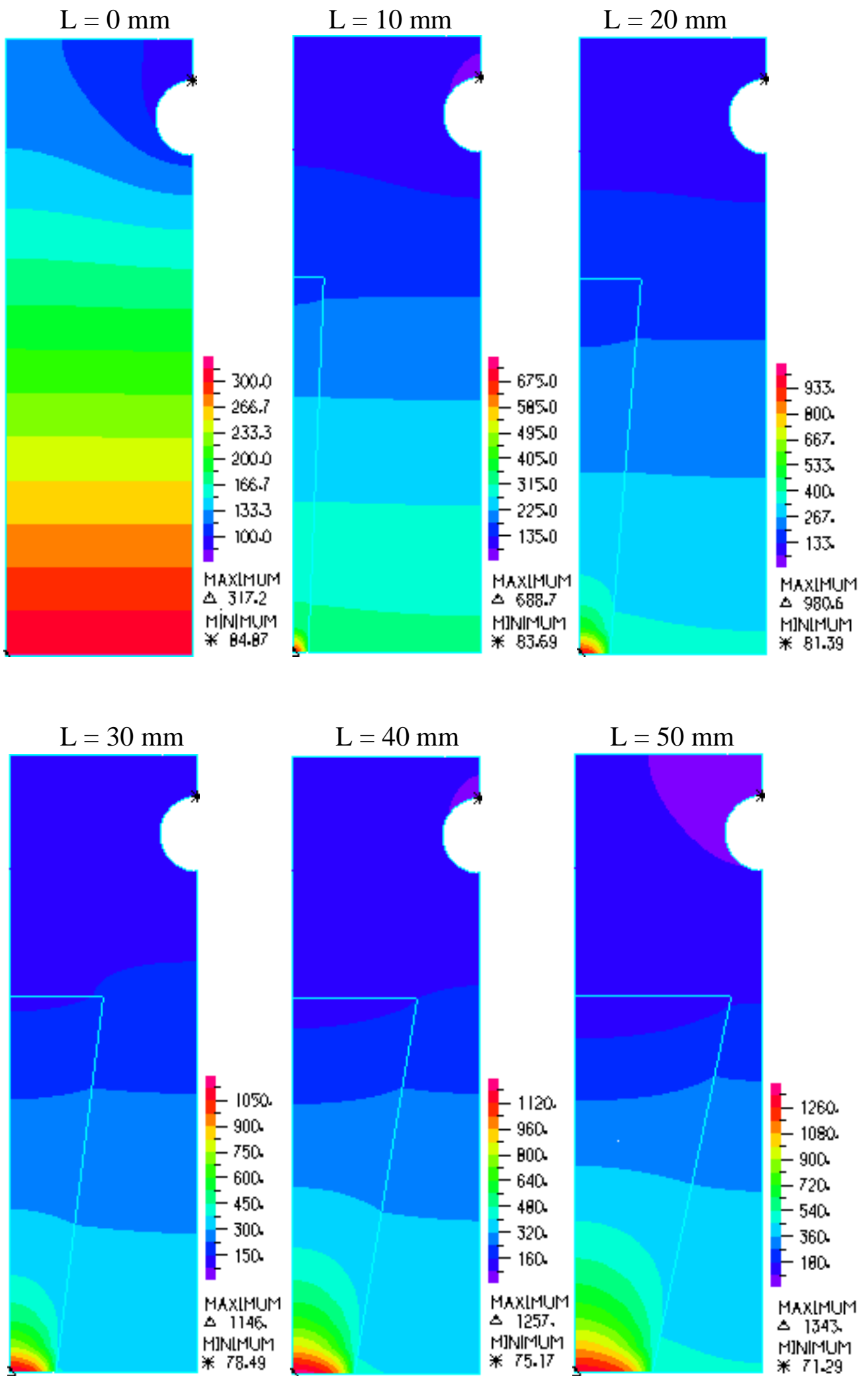

Figure 11. Effect of slanted brick material thickness on the isotherms $\left(k=2.9 \mathrm{~W} / \mathrm{m}^{\circ} \mathrm{C}\right)$ 


\section{CONCLUSION}

A numerical investigation was carried out to study the effect of using refractory brick materials on the temperature variations along the bottom and top surfaces of the electric arc furnace. Moreover, the isotherms were presented for various dimensions of the refractory materials. The results of this investigation showed that the maximum top surface temperature decreases significantly with decreasing the thermal conductivity of the refractory material. Moreover, rectangular alumina material was found more effective than the wedge material.

\section{NOMENCLATURE}

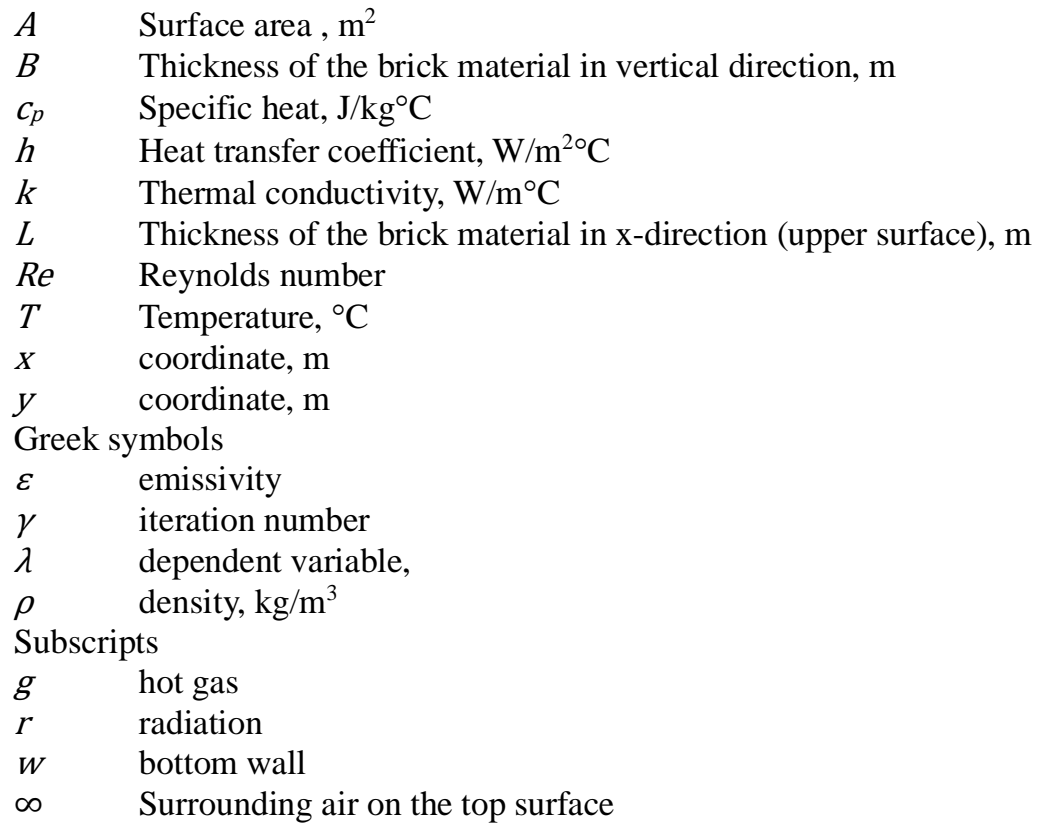

\section{REFERENCES}

[1] Dal Magro F, Meneghetti A, Nardin G, Savino S. Enhancing energy recovery in the steel industry: matching continuous charge with off-gas variability smoothing. Energy Convers Manage 2015; 104:78-89. doi.org/10.1016/j.enconman.2015.05.012.

[2] Kirschen M, Velikorodov V, Pfeifer H. Mathematical modelling of heat transfer in dedusting plants and comparison to off-gas measurements at electric arc furnaces. Energy 2006; 31:2926-39. doi.org/10.1016/j.energy.2005.12.006.

[3] Horia A, Costin C, Sorin G. Power Quality and Electrical Arc Furnaces. ISBN: 978-953-307-180-0, InTech Open 2011; 77-100, doi: 10.5772/15996.

[4] Math H Bollen, Irene Yu-Hua Gu. Signal Processing of Power Quality Disturbances, New York; WileyInterscience; 2006. doi:10.1002/0471931314

[5] Hooshmand R, Esfahani M. Optimal design of TCR/FC in electric arc furnaces for power quality improvement in power systems. Leonardo Electronic Journal of Practices and Technologies 2009; 15:31-50.

[6] Lazaroiu C, Zaninelli D. DC arc furnace modeling for power quality analysis. Scientific Bulletin of Politehnica, University of Bucharest 2010; C72 :56-62.

[7] Makarov A, Sukolov A. Electric, ecometric and thermal parameters of the arcs glowing in metal vapor. Elektrometallurigiya 2009; 11:19-24.

[8] Makarov A, Rybakova V, Galicheva M. Electromagnetism and the arc efficiency of electric arc steel melting furnaces. Journal of Electromagnetic Analysis and Applications 2014; 6:184 - 192. doi: 10.4236/jemaa.2014.67018.

[9] Karel V, Andrew K, Kyllo F, Bart B, Patrick W. Furnace Cooling technology in pyrometallurgical processes. Sohn International Symposium Advanced Processing of Metals and Materials 2006; 4:139-154.

[10] Erfan K, Alireza R, Marc A Rosen, Zabihollah A, Omid A, Amir M. Experimental and numerical investigations on heat transfer of a water-cooled lance for blowing oxidizing gas in an electrical arc furnace. Energy 
Conversion and Management 2017; 148:43-56. doi.org/10.1016/j.enconman.2017.05.057.

[11] Chirattananon S, Gao Z. A model for the performance evaluation of the operation of electric arc furnace. Energy Conversion and Management 1996; 37:161-6. doi.org/10.1016/0196-8904(95)00173-B.

[12] Afshin G, Mombeni E, Hajidavalloo, Behbahani N. Transient simulation of conjugate heat transfer in the roof cooling panel of an electric arc furnace. Applied Thermal Engineering 2016; 98:80-87. doi.org/10.1016/j.applthermaleng.2015.12.004.

[13] Bisio G, Rubatto G, Martini R. Heat transfer, energy saving and pollution control in UHP electric-arc furnaces. Energy 2000; 25:1047-66. doi.org/10.1016/S0360-5442(00)00037-2.

[14] Nikolov M. Research on the impact of amplitude of vibrations on electrical parameters of vibroarc weld overlay in Argon. Acta Technologica Agriculturae 2015; 2:46-48. doi: 10.1515/ata-2015-0010.

[15] Tsujimura Y, Tanaka M. Analysis of behavior of arc plasma conditions in MIG welding with metal transfer visualization o phenomena of welding arc by imaging spectroscopy. Quarterly Journal of The Japan Welding Society 2012; 30:288-297. doi.org/10.2207/qjjws.30.288.

[16] Murphy A. A perspective on arc welding research: the importance of the arc, unresolved questions and future directions. Plasma Chemistry and Plasma Processing 2015; 35:471-489. doi.org/10.1007/s11090-015-9620-2.

[17] Choudhary M. Three-dimensional mathematical model for flow and heat transfer in electric glass furnace. Heat Transfer Engineering 1985; 6:55-65. doi.org/10.1080/01457638508939639.

[18] Yu J, Zhan M. Modeling and experiments for heat transfer process in pulverized coal-firing furnace with twodimensional radiation characteristics. Heat Transfer Engineering 2009; 30:988-997. doi.org/ 10.1080/01457630902837475.

[19] Hiraoka K, Shiwaku T, Ohj T. Temperature distributions of gas tungsten Arc plasma by spectroscopic methods. Quarterly Journal of The Japan Welding Society 1996; 14:641-648. doi: 10.2207/qjjws.29.274

[20] Nomura K, Kishi T, Shirai K, Hirata Y, Kataoka K. Temperature measurement of asymmetrical pulsed TIG arc plasma by multidirectional monochromatic imaging method. Welding in the World 2015; 59:283-293. doi.org/10.1007/s40194-014-0211-2.

[21] Boselli M, Colombo V, Ghedini E, Gherardi M, Sanibondi P. Two-temperature modelling and optical emission spectroscopy of a constant current plasma arc welding process. Journal of Physics D: Applied Physics 2013; 46:224009. doi.org/10.1088/0022-3727/46/22/224009.

[22] Shigeta M, Nakanishi S, Tanaka M, Murphy A. Analysis of dynamic plasma behaviors in gas metal arc welding by imaging spectroscopy. Quarterly Journal of The Japan Welding Society 2015; 33:118-125. doi.org/10.2207/qjjws.33.118.

[23] Bachmann M, Avilov V, Gumenyuk A. Rethmeier M. Experimental and numerical investigation of an electromagnetic weld pool support system for high power laser beam welding of austenitic stainless steel. Journal of Materials Processing Technology 2014; 214:578-591. doi.org/10.1016/j.jmatprotec.2013.11.013.

[24] Ogino Y, Nomura K, Hirata Y. Numerical analysis of arc plasma behavior in groove welding with 3D TIG arc model. Welding Internationall 2013; 27:867-873. doi: 10.1080/09507116.2012.715876.

[25] Kanemaru S, Sasaki T, Sato T, Mishima H, Tashiro S, Tanaka M. Study for the arc phenomena of TIG-MIG hybrid welding process by 3D numerical analysis model. Quarterly Journal of The Japan Welding Society 2012; 30:323-330. doi.org/10.2207/qjjws.30.323.

[26] Üstündag Ö, Avilov V, Gumenyuk A, Rethmeier M. Full penetration hybrid laser arc welding of up to $28 \mathrm{~mm}$ thick S355 plates using electromagnetic weld pool support. Journal of Physics:Conf. Series 2018; 1109 012015. doi :10.1088/1742-6596/1109/1/012015.

[27] Contreras-Serna J, Rivera-Solorio C, Herrera-Garcia M. Study of heat transfer in a tubular-panel cooling system in the wall of an electric arc furnace. Applied Thermal Engineering 2019; 148:43-56. doi.org/10.1016/j.applthermaleng.2018.10.134.

[28] Optiz F, Treffinger P, Wollenstein J. Modeling of radiative heat transfer in an electric arc furnace. Metallurgical and Materials Transactions B 2017; 48:3301-3315. doi.org/10.1007/s11663-017-1078-6.

[29] Khodabandeh E, Ghaderi M, Afzalabadi A, Rouboa A, Salarifard A. Parametric study of heat transfer in an electric arc furnace and cooling system. Applied Thermal Engineering 2017; 123:1190-1200. doi.org/10.1016/j.applthermaleng.2017.05.193.

[30] Mehrabian R, Shiehnejadhesar A, Scharler R. Application of numerical modelling to biomass grate furnaces. Journal of Thermal Engineering 2015; 1:550-556. doi:10.18186/jte.85878.

[31] Sert S, Balkan F. Determination of avoidable and unavoidable exergy analysis destruction of furnace-air preheater coupled system in petrochemical plant. Journal of Thermal Engineering 2016; 2:794-800.

[32] Baehr, H D, Stephan K. Heat and Mass Transfer, Springer; 2006. doi:10.1007/3-540-29527-5. 